\title{
The Real Story Behind Story Problems: Effects of Representations on Quantitative Reasoning
}

\author{
Kenneth R. Koedinger \\ Human-Computer Interaction Institute \\ Carnegie Mellon University \\ Mitchell J. Nathan \\ School of Education \\ University of Colorado
}

\begin{abstract}
This article explores how differences in problem representations change both the performance and underlying cognitive processes of beginning algebra students engaged in quantitative reasoning. Contrary to beliefs held by practitioners and researchers in mathematics education, students were more successful solving simple algebra story problems than solving mathematically equivalent equations. Contrary to some views of situated cognition, this result is not simply a consequence of situated world knowledge facilitating problem-solving performance, but rather a consequence of student difficulties with comprehending the formal symbolic representation of quantitative relations. We draw on analyses of students' strategies and errors as the basis for a cognitive process explanation of when, why, and how differences in problem representation affect problem solving. We conclude that differences in external representations can affect performance and learning when one representation is easier to comprehend than another or when one representation elicits more reliable and meaningful solution strategies than another.
\end{abstract}

A commonly held belief about story problems at both the arithmetic and algebra levels is that they are notoriously difficult for students. Support for this belief can be seen among a variety of populations including the general public, textbook au-

Correspondence and requests for reprints should be sent to Kenneth R. Koedinger, Human-Computer Interaction Institute, Carnegie Mellon University, Pittsburgh, PA 15213. E-mail: koedinger@cmu.edu 
thors, teachers, mathematics education researchers, and learning science researchers. For evidence that this belief is commonly held within the general public, ask your neighbor. He or she is likely to express a sentiment along the lines of Gary Larson's cartoon captioned "Hell's Library" that contains bookshelves full of titles such as "Story Problems," "More Story Problems," and "Story Problems Galore." That many textbook authors believe in the greater difficulty of story problems is supported by an analysis of textbooks by Nathan, Long, and Alibali (2002). In 9 of the 10 textbooks they analyzed, new topics are initially presented through symbolic activities and only later are story problems presented, often as challenge problems. This ordering is consistent with the belief that symbolic representations are more accessible to students than are story problems.

More direct evidence of the common belief in the difficulty of story problems comes from surveys of teachers and mathematics educators. In a survey of $67 \mathrm{high}$ school mathematics teachers, Nathan and Koedinger (2000a) found that most predicted that story problems would be harder than matched equations for algebra students. Nathan and Koedinger (2000a) also surveyed 35 mathematics education researchers, the majority of which also predicted that story problems would be harder than matched equations for algebra students. In another study of $105 \mathrm{~K}-12$ mathematics teachers, Nathan and Koedinger (2000b) found that significantly more teachers agree than disagree with statements such as "Solving math problems presented in words should be taught only after students master solving the same problems presented as equations." This pattern was particularly strong among the high school teachers in the sample $(n=30)$.

Belief in the difficulty of story problems is also reflected in the learning science literature. Research on story problem solving, at both the arithmetic (Carpenter, Kepner, Corbitt, Lindquist, \& Reys, 1980; Cummins, Kintsch, Reusser, \& Weimer, 1988; Kintsch \& Greeno, 1985) and algebra levels (Clement, 1982; Nathan, Kintsch, \& Young, 1992; Paige \& Simon, 1966), has emphasized the difficulty of such problems. For instance, Cummins and colleagues (1988, p. 405) commented that "word problems are notoriously difficult to solve." They investigated first graders' performance on matched problems in story and numeric format for 18 categories of one-operator arithmetic problems. Students were $27 \%$ correct on the Compare 2 problem in story format ("Mary has 6 marbles. John has 2 marbles. How many marbles does John have less than Mary?") but were 100\% correct on the matched numeric format problem $6-2=$ ?. Cummins et al. found performance on story problems was worse than performance on matched problems in numeric format for 14 of the 18 categories and was equivalent for the remaining 4 categories. Belief in the greater difficulty of story problems is also evident in the broader developmental literature. For instance, Geary (1994, p. 96) states that "children make more errors when solving word problems than when solving comparable number problems."

Although their research addressed elementary-level arithmetic problem solving, Cummins et al. (1988, p. 405) went on to make the broader claim that "as stu- 
dents advance to more sophisticated domains, they continue to find word problems in those domains more difficult to solve than problems presented in symbolic format (e.g., algebraic equations)." However, apart from our own studies reported here, this broader claim appears to remain untested (cf. Reed, 1998). We have not found prior experimental comparisons of solution correctness on matched algebra story problems and equations for students learning algebra. In a related study, Mayer (1982a) used solution times to make inferences about the different strategies that well-prepared college students use on algebra word and equation problems. He found a different profile of solution times for word problems than for equations as problems varied in complexity and accounted for these differences by the hypothesis that students use a goal-based "isolate" strategy on equations and a less memory-intensive "reduce" strategy on word problems. Overall, students took significantly longer to solve one- to five-step word problems (about $15 \mathrm{sec}$ ) than matched equations (about $5 \mathrm{sec}$ ) with no reliable difference in number of errors (7\% for word problems, $4 \%$ for equations). Whereas Mayer's study focused on timing differences for well-practiced participants, the studies reported here focus on error differences for beginning algebra students.

\section{WHY ARE STORY PROBLEMS DIFFICULT?}

What might account for the purported and observed difficulties of story problems? As many researchers have observed (Cummins et al., 1988; Hall et al., 1989; Lewis \& Mayer, 1987; Mayer, 1982b), the process of story problem solving can be divided into a comprehension phase and a solution phase (see Figure 1). In the comprehension phase, problem solvers process the text of the story problem and create corresponding internal representations of the quantitative and situation-based relationships expressed in that text (Nathan et al., 1992). In the solution phase problem solvers use or transform the quantitative relationships that are represented both internally and externally to arrive at a solution. Two kinds of process explanations for the difficulty of story problems correspond with these two problem-solving phases. We will return to these explanations after describing how these two phases interact during problem solving (for more detail see Koedinger \& MacLaren, 2002).

The comprehension and solution phases typically are interleaved rather than performed sequentially. Problem solvers iteratively comprehend first a small piece of the problem statement (e.g., a clause or sentence) and then produce a piece of corresponding external representation (e.g., an arithmetic operation or algebraic expression), often as an external memory aid. In Figure 1, the double-headed arrows within the larger arrows are intended to communicate this interactivity. During problem solving, aspects of newly constructed internal or external representations may influence further comprehension in later cycles (Kintsch, 1998). For example, after determining that the unknown value is the number of donuts, the 


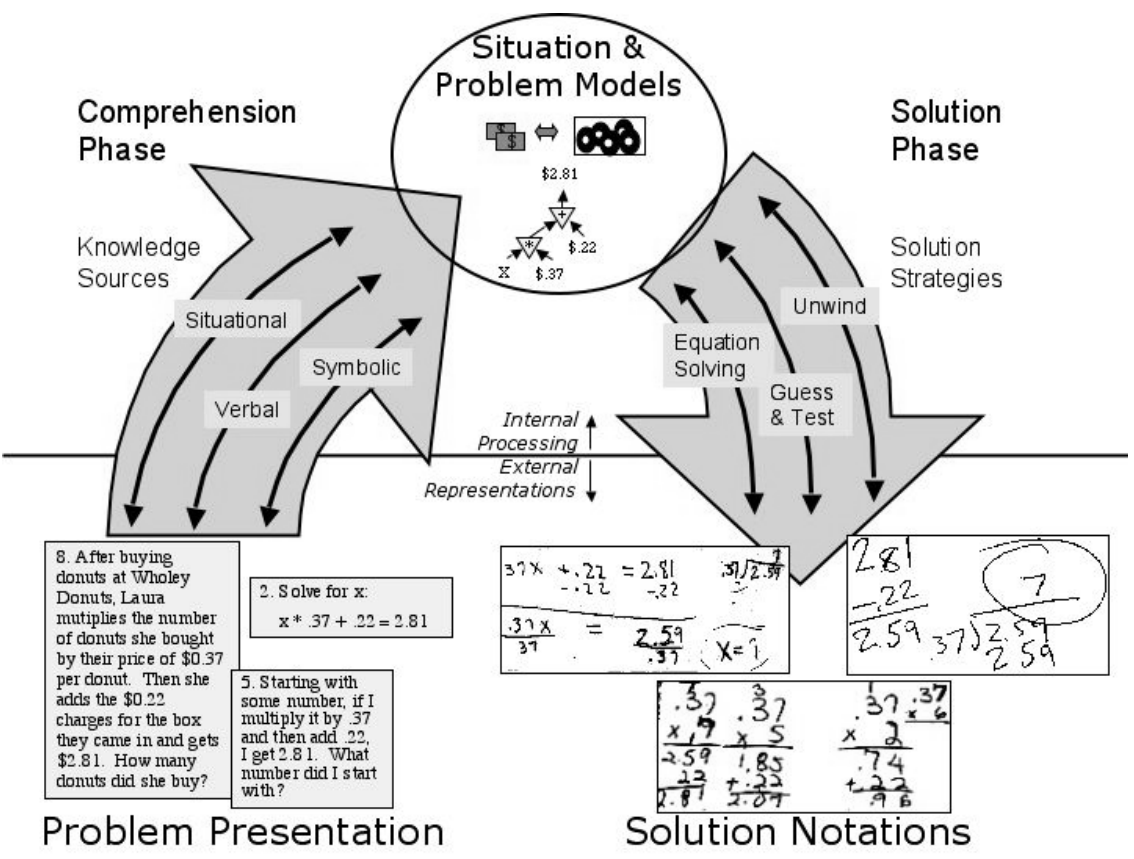

FIGURE 1 Quantitative problem solving involves two phases, comprehension and solution, both of which are influenced by the external representation (e.g., story, word, equation) in which a problem is presented. The influence on the comprehension phase results from the need for different kinds of linguistic processing knowledge (e.g., situational, verbal, or symbolic) required by different external representations. The impact on the solution phase results from the different computational characteristics of the strategies (e.g., unwind, guess-and-test, equation solving) cued by different external representations.

reader may then search for and reread a clause that uses number of donuts in a quantitative relation. Similarly, the production of aspects of the external representation may help maintain internal problem-solving goals that, in turn, may direct further comprehension processes.

A number of researchers have provided convincing evidence that errors in the comprehension phase well account for story problem solving difficulties (e.g., Cummins et al., 1988; Lewis \& Mayer, 1987). For instance, Cummins et al. (1988) demonstrated that variations in first graders' story problem performance were well predicted by variations in problem recall and that both types of variation could be accounted for by difficulties students had in comprehending specific linguistic forms such as some, more $\mathrm{X}$ s than $\mathrm{Ys}$, and altogether. They concluded that "text comprehension factors figure heavily in word problem difficulty" (p. 435). Lewis and Mayer 
(1987) summarized past studies with K-6 graders and their own studies with college students that showed more solution errors on arithmetic story problems with "inconsistent language" (e.g., when the problem says "more than" but subtraction is required to solve it) than problems with consistent language. Teachers' intuitions about the difficulty of algebra story problems (cf. Nathan \& Koedinger, 2000a, 2000b) appear to be in line with these investigations of comprehension difficulties with arithmetic story problems. As one teacher explained, "Students are used to expressions written algebraically and have typically had the most practice with these ... translating 'English' or 'non-mathematical' words is a difficult task for many students."

A second process explanation for the difficulty of story problems focuses on the solution phase, particularly on the strategies students use to process aspects of the problem. A common view of how story problems are or should be solved, particularly at the algebra level, is that the problem text first is translated into written symbolic form and then the symbolic problem is solved (e.g., see Figure 2a). If problem solvers use this translate-and-solve strategy, then clearly story problems will be harder than matched symbolic problems because solving the written symbolic problem is an intermediate step in this case.

At the algebra level, the translate-and-solve strategy has a long tradition as the recommended approach. Regarding an algebra-level story problem, Paige and Simon (1966) comment, "At a common-sense level, it seems plausible that a person solves such problems by, first, translating the problem sentences into algebraic equations and, second, solving the equations." They go on to quote a 1929 textbook recommending this approach (Hawkes, Luby, \& Touton, 1929). Modern textbooks also recommend this approach and typically present story problems as challenge problems and applications in the back of problem-solving sections (Nathan, Long, et al., 2002). Thus, a plausible source for teachers' belief in the difficulty of story problems over equations is the idea that equations are needed to solve story problems. An algebra teacher performing the problem difficulty ranking task described in Nathan and Koedinger (2000a) made the following reference to the translate-and-solve strategy (the numbers 1-6 refer to sample problems teachers were given; Table 1 shows these sample problems):

" 1 [the arithmetic equation] would be a very familiar problem ... Same for 4 [the algebra equation] ... 3 [the arithmetic story] and 6 [the algebra story] add context ... Students would probably write 1 or 4 [equations] from any of the others before proceeding."

\section{STORY PROBLEMS CAN BE EASIER}

Some studies have identified circumstances where story problems are easier to solve than equations. Carraher, Carraher, \& Schliemann (1987) found that 
8. After buying donuts at Wholey Donuts, Laura muitiplies the number of donuts she bought by their price of $\$ 0.37$ per donut. Then she adds the $\$ 0.22$ charge for the box they came in and gets $\$ 2.81$. How many donuts did she buy?

$$
\begin{aligned}
& . 3 7 x + . 2 2 = 2 . 8 1 \quad . 3 7 \longdiv { \frac { 1 } { 2 . 5 9 } } \\
& -.22 \quad-22 \\
& \frac{.37 x}{31}=\frac{2.59}{.37} \quad x=1
\end{aligned}
$$

a. The normative strategy: Translate to algebra and solve algebraically

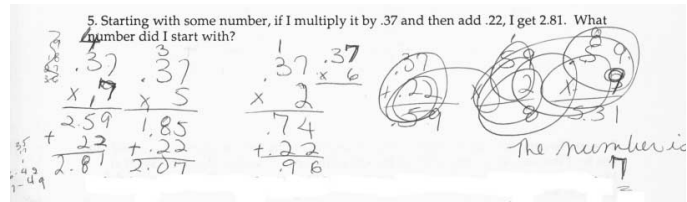

b. The guess-and-test strategy.
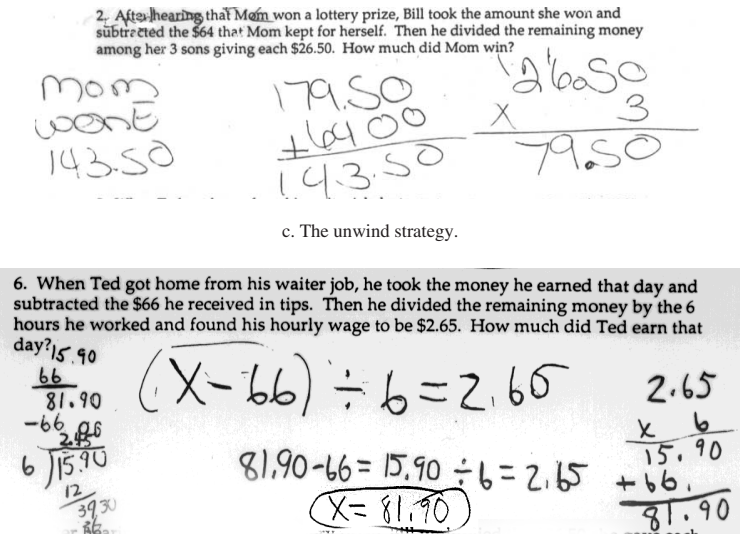

d. Translation to an algebra equation, which is then solved by the informal, unwind

strategy.

7. After hearing that Mom won a lottery prize, Birt muluplied the $\$ 26.50$ she gave each son by 3 (because all 3 sons received the same amount). Then he added the $\$ 64$ that Mom kept for herself and found the total amount Mom won. How much did Mom win?

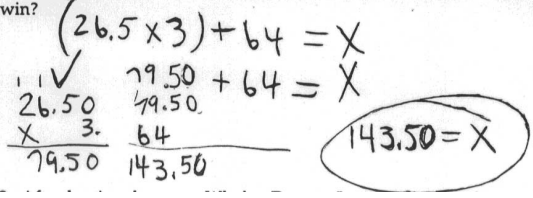

e. A rare translation of a result-unknown story to an equation.

FIGURE 2 Examples of successful strategies used by students: (a) guess-and-test, (b) unwind, (c) translate to algebra and solve algebraically, (d) translate to algebra and solve by unwind, (e) translate to algebra and solve by arithmetic. 
TABLE 1

Six Problem Categories Illustrating Two Difficulty Factors: Representation and Unknown-Position

\begin{tabular}{|c|c|c|}
\hline Story Problem & Word Equation & Symbolic Equation \\
\hline \multicolumn{3}{|l|}{ Result—unknown } \\
\hline $\begin{array}{l}\text { When Ted got home from his waiter job, he } \\
\text { took the } \$ 81.90 \text { he earned that day and } \\
\text { subtracted the } \$ 66.00 \text { he received in tips. } \\
\text { Then he divided the remaining money by } \\
\text { the } 6 \mathrm{hr} \text { he worked and found his hourly } \\
\text { wage. How much does Ted make per hour? }\end{array}$ & $\begin{array}{l}\text { Starting with } 81.9 \text {, if I } \\
\text { subtract } 66 \text { and then } \\
\text { divide by } 6, \text { I get a } \\
\text { number. What is it? }\end{array}$ & $\begin{array}{l}\text { Solve for } x \text { : } \\
\qquad(81.90-66) / 6=x\end{array}$ \\
\hline \multicolumn{3}{|l|}{ Start-unknown } \\
\hline $\begin{array}{l}\text { When Ted got home from his waiter job, he } \\
\text { multiplied his hourly wage by the } 6 \mathrm{hr} \text { he } \\
\text { worked that day. Then he added the } \$ 66.00 \\
\text { he made in tips and found he had earned } \\
\$ 81.90 \text {. How much does Ted make per hour? }\end{array}$ & $\begin{array}{l}\text { Starting with some } \\
\text { number, if I multiply it } \\
\text { by } 6 \text { and then add } 66, \text { I } \\
\text { get } 81.9 \text {. What number } \\
\text { did I start with? }\end{array}$ & $\begin{array}{l}\text { Solve for } x \text { : } \\
\qquad x \times 6+66=81.90\end{array}$ \\
\hline
\end{tabular}

Brazilian third graders were much more successful solving story problems (e.g., "Each pencil costs $\$ .03$. I want 40 pencils. How much do I have to pay?") than solving matched problems presented symbolically (e.g., $3 \times 40$ ). Baranes, Perry, and Stigler (1989) used the same materials with U.S. third graders. U.S. children had higher overall success than the Brazilian children and, unlike the Brazilian children, did not perform better in general on story problems than on symbolic problems. However, Baranes and colleagues (1989) demonstrated specific conditions under which the U.S. children did perform better on story problems than on symbolic ones, namely, money contexts and numbers involving multiples of 25 , corresponding to the familiar value of a quarter of a dollar.

If story problems are sometimes easier as the Carraher et al. (1987) and Baranes et al. (1989) results suggest, what is it about the story problem representation that can enhance student performance? Baranes and colleagues (1989) hypothesized that the situational context of story problems can make them easier than equivalent symbolic problems and suggested that the problem situation activates real-world knowledge ("culturally constituted systems of quantification," p. 316) that aids students in arriving at a correct solution.

Such an advantage of stories over symbolic forms can be explained within the solution phase of the problem-solving framework presented in Figure 1. Story problems can be easier when stories elicit different, more effective solution strategies than those elicited by equations. Past studies have demonstrated that different strategies can be elicited even by small variations in phrasing of the same story. For example, Hudson (1983) found that nursery school children were $17 \%$ correct on a standard story phrasing, "There are 5 birds and 3 worms. How many more birds are 
there than worms?" However, performance increased to an impressive $83 \%$ when the story is phrased as, "There are 5 birds and 3 worms. How many birds don't get a worm?" The latter phrasing elicits a match-and-count strategy that is more accessible for novice learners than the more sophisticated subtraction strategy elicited by the former, more standard phrasing.

The notion of a situation model (Kintsch \& Greeno, 1985; Nathan et al., 1992) provides a theoretical account of how story problems described in one way can elicit different strategies than do equations or story problems described in other ways. In this account, problem solvers comprehend the text of a story problem by constructing a model-based representation of actors and actions in the story. Differences in the stories tend to produce differences in the situation models, which in turn can influence the selection and execution of alternative solution strategies. By this account, it is the differences in these strategies at the solution phase (see Figure 1) that ultimately accounts for differences in performance. For instance, Nunes, Schliemann, and Carraher (1993) found that everyday problems were more likely to evoke oral solution strategies whereas symbolic problems evoked less effective written arithmetic strategies.

Process model developers of story problem solving (e.g., Bobrow, 1968; Cummins et al., 1988; Mayer, 1982b) have been careful to differentiate comprehension versus solution components of story problem solving. However, readers of the literature might be left with the impression that equation solving involves only a solution phase; in other words, that comprehension is not necessary. Although it is tempting to think of comprehension as restricted to the processing of natural language, clearly other external forms, such as equations, charts, and diagrams (cf. Larkin \& Simon, 1987), must be understood or comprehended to be used effectively to facilitate reasoning. The lack of research on student comprehension of number sentences or equations may result from a belief that such processing is transparent or trivial for problem solvers at the algebra level. Regarding equations such as $(81.90-66) / 6=x$ and $x \times 6+66=81.90$ in Table 2, an algebra teacher commented that these could be solved "without thinking."

\section{HYPOTHESES AND EXPERIMENTAL DESIGN}

The two studies presented here are the first we know of that test the common belief that algebra learners have greater difficulty with story problems than matched equations. ${ }^{1}$ Table 1 shows examples of the main factors manipulated in these studies. In addition to the main contrast between story problems and equations (first

\footnotetext{
${ }^{1}$ Recent reviews of mathematics learning research (Kilpatrick, Swafford, \& Findell, 2001), story problem research (Reed, 1998), and algebra research (Bednarz, Kieran, \& Lee, 1996; Kieran, 1992) do not reference any such studies.
} 
TABLE 2

Examples of the Four Cover Stories Used

Story Problem Cover Stories

\begin{tabular}{|c|c|c|c|}
\hline Donut & Lottery & Waiter & Basketball \\
\hline $\begin{array}{l}\text { After buying donuts at } \\
\text { Wholey Donuts, Laura } \\
\text { multiplies the } 7 \text { donuts } \\
\text { she bought by their } \\
\text { price of } \$ 0.37 \text { per } \\
\text { donut. Then she adds } \\
\text { the } \$ 0.22 \text { charge for } \\
\text { the box they came in } \\
\text { and gets the total } \\
\text { amount she paid. How } \\
\text { much did she pay? }\end{array}$ & $\begin{array}{l}\text { After hearing that Mom } \\
\text { won a lottery prize, } \\
\text { Bill took the } \$ 143.50 \\
\text { she won and subtracted } \\
\text { the } \$ 64.00 \text { that Mom } \\
\text { kept for herself. Then } \\
\text { he divided the } \\
\text { remaining money } \\
\text { among her } 3 \text { sons } \\
\text { giving each the same } \\
\text { amount. How much did } \\
\text { each son get? }\end{array}$ & $\begin{array}{l}\text { When Ted got home from } \\
\text { his waiter job, he } \\
\text { multiplied his wage of } \\
\$ 2.65 \text { per hour by the } 6 \\
\text { hr he worked that day. } \\
\text { Then he added the } \\
\$ 66.00 \text { he made in tips } \\
\text { and found how much } \\
\text { he earned. How much } \\
\text { did Ted earn that day? }\end{array}$ & $\begin{array}{l}\text { After buying a basketball } \\
\text { with his daughters, Mr. } \\
\text { Jordan took the price of } \\
\text { the ball, } \$ 68.36 \text {, and } \\
\text { subtracted the } \$ 25 \text { he } \\
\text { contributed. Then he } \\
\text { divided the rest by } 4 \text { to } \\
\text { find out what each } \\
\text { daughter paid. How } \\
\text { much did each } \\
\text { daughter pay? }\end{array}$ \\
\hline
\end{tabular}

and last columns in Table 1), we added an intermediate problem representation we refer to as word problems or word equations (middle column in Table 1). We included word equations to isolate effects of situational knowledge from effects of differences in language comprehension demands between verbal and symbolic forms. If stories cue useful situational knowledge, then we should find students making fewer errors on story problems than on both word and symbolic equations. If students' relevant symbolic comprehension skills lag behind their relevant verbal comprehension skills, then we should find them making more errors on symbolic equations than on either of the verbal forms.

Our goal was to explore representation effects for students at the transition from arithmetic to algebraic competence-a domain referred to as "early algebra" (cf. Carpenter \& Levi, 1999; Kaput, in press). Thus, we included both relatively complex arithmetic problems (first row in Table 1) and relatively simple algebra problems (second row in Table 1). In the arithmetic problems, the problem unknown is the result of the process or sequence of operators described. These result-unknown problems are more complex than those used in prior research on elementary arithmetic problem solving (Briars \& Larkin, 1984; Carpenter \& Moser, 1984; Hiebert, 1982; Riley \& Greeno, 1988). These problems involve two arithmetic operators (e.g., multiplication and addition) rather than one, decimals rather than only whole numbers, and more advanced symbolic notation such as parentheses and equations with a variable on the right side (e.g., $[81.90-66] / 6=x$ ). The relatively simple algebra problems we used are two-operator start-unknowns, that is, problems where the unknown is at the start of the arithmetic process described. 
These problems are not meant to be representative of all kinds of algebraic thinking or even all kinds of algebraic problem solving. As others have well noted (cf. Carpenter \& Levi, 1999; Kaput, in press), algebraic thinking involves more than problem solving and includes study of functional relations, covariation, graph comprehension, mathematical modeling and symbolization, and pattern generalization. Even within the smaller area of algebraic problem solving, there is a large variety of problems. Others have explored classes of algebra problems more difficult than the ones used, for instance, problems where the unknown is referenced more than once and possibly on both sides of the equal sign, such as $5.8 x-25=5.5 x$ (e.g., Bednarz \& Janvier, 1996; Kieran, 1992; Koedinger, Alibali, \& Nathan, submitted). Still others have begun to explore simpler classes of problems that may draw out algebraic thinking in elementary students (e.g., Carpenter \& Levi, 1999; Carraher, Schliemann, \& Brizuela, 2000).

Our review of the literature on story problem solving leads us to consider three competing hypotheses regarding the effects of problem representation on quantitative problem solving at the early algebra level. The symbolic facilitation hypothesis is consistent with the common belief that equations should be easier than matched story problems because difficult English-language comprehension demands are avoided (Cummins et al., 1988) and because the solution step of translating the problem statement to an equation is eliminated (Paige \& Simon, 1966). The situation facilitation hypothesis follows from the idea that story representations can cue knowledge that facilitates effective strategy selection and execution (cf. Baranes et al., 1989; Carraher et al., 1987). Note that the four cover stories we used, shown in Table 2, all involve money quantities and familiar contexts for junior high age students. The situation facilitation hypothesis predicts that students will make fewer errors on story problems than on situation-free word equations and equations.

A third verbal facilitation hypothesis follows from the observation that algebra equations are not transparently understood and that the equation comprehension skills of beginning algebra students may lag behind their existing English-language comprehension skills. The verbal facilitation hypothesis predicts that students will make fewer errors on story and word equations than on more abstract equations. The verbal facilitation claim is similar to the situational facilitation and the culturally bound results of Carraher et al. (1987) and Baranes et al. (1989): In some cases, situational knowledge helps elementary students perform better on story problems than on matched equations. For algebra students, however, it is not simply situation knowledge that can make story problems easier. Rather, the increased demands on symbolic comprehension presented by equations lead to difficulties for algebra students who have by now mostly mastered the English-comprehension knowledge needed for matched verbally stated problems. The verbal facilitation hypothesis uniquely predicts 
that both word equations and story problems can be easier than matched equations. $^{2}$

In contrast with the idea that equations are transparently understood, a key point of this article is to test the claim that comprehension of algebra equations is not trivial for algebra learners and that, as a consequence, algebra story problems can sometimes be easier to solve than matched equations. The verbal facilitation claim directly contradicts the documented views of many teachers and education researchers (Nathan \& Koedinger, 2000a, 2000b) and cognitive scientists (e.g., Cummins et al., 1988; Geary, 1994) that algebra story problems are inherently more difficult than matched equations. This claim also addresses a gap in past theoretical analyses of quantitative reasoning that have provided story comprehension models (e.g., Bobrow, 1968; Cummins et al., 1988; Kintsch \& Greeno, 1985; Nathan, Kintsch, \& Young, 1992) but have neglected equation comprehension. These models did not address the possibility that the equation format may present greater comprehension challenges for learners than analogous verbal forms (cf. Kirshner, 1989; Sleeman, 1984).

\section{DIFFICULTY FACTORS ASSESSMENTS: STUDIES 1 AND 2}

We investigated the symbolic, situation, and verbal facilitation hypotheses in two studies. In both studies, students were asked to solve problems selected from a multidimensional space of problems systematically generated by crossing factors expected to influence the degree of problem difficulty. In addition to the problem representation and unknown position factors shown in Table 1, we also manipulated the type of numbers involved (whole numbers vs. positive decimals) and the final arithmetic that problems required (multiplication and addition vs. subtraction and division). We refer to this methodology as Difficulty Factors Assessment (DFA) (Heffernan \& Koedinger, 1998; Koedinger \& MacLaren, 2002; Koedinger \& Tabachneck, 1995; Verzoni \& Koedinger, 1997) and the two studies described here as DFA1 and DFA2.

\section{Methods for DFA1 and DFA2}

Participants. Seventy-six students from an urban high school participated in DFA1. Of these students, 58 were enrolled in one of three mainstream Algebra 1

\footnotetext{
${ }^{2}$ Combinations of the symbolic, situation, and verbal facilitation hypotheses are possible. For instance, combining symbolic and situation facilitation predicts that story problems and equations will be easier than word equations. Alternatively, combining situation and verbal facilitation predicts that story problems will be easier than word equations and, in turn, word equations will be easier than equations.
} 
classes, and 18 were ninth graders enrolled in a geometry class who had taken Algebra 1 in eighth grade. Four teachers taught the classes. The DFA2 participants were 171 students sampled from 24 classrooms at three urban high schools. All students were in a first-year Algebra 1 course. Twelve teachers taught the 24 classroom sections.

Form design. Ninety-six problems were created using 4 cover stories that systematically varied 4 difficulty factors: 3 levels of problem presentation (story, word equation, and symbol equation) $\times 2$ levels of unknown positions (result vs. start) $\times 2$ number types (whole vs. decimal) $\times 2$ final arithmetic types (multiplication and addition vs. subtraction and division). Table 3 shows the cross table for these factors; each cell is a different problem. Problems in the same column have a common underlying mathematical structure, as indicated in the Base Equation row. For instance, all integer Donut problems (fourth column of Table 3 ) are based on the equation $4 \times 25+10=\mathbf{1 1 0}$. The answer for each problem is one of these bold numbers. When the final arithmetic is multiply-add (see $\times,+$ in the third column), the answer is the last number (e.g., 110); when it is subtract-divide (-,/), the answer is the first number (e.g., 4). The unknown position (second column), as described previously, determines whether the unknown is the result or the start of the arithmetic operations described in the problem. The appearance to students of the result-unknown, subtract-divide problems (e.g., $[110-10] / 25=x$ ) and start-unknown, multiply-add problems (e.g., $[x-10] / 25=4$ ) is the reverse of that shown in the base equation form.

The 96 problems were distributed onto 16 forms with 8 problems on each form. We limited the number of items per form because prior testing revealed that 8 problems could be reasonably completed in less than half a class period (18 min). This decision reflected teachers' recommendations for reasonable quiz duration and for use of class time relative to the demands of the required curriculum.

Placement of problems on forms met the following constraints. Each form included two story result-unknowns, two story start-unknowns, one word equation result-unknown, one word equation start-unknown, one equation result-unknown, and one equation start-unknown. Each form had one problem from a particular base equation (one from each column in Table 3) such that no numbers or answers were repeated on any form. The four story problems on every form had either all integer number types or all decimal number types. The four other problems had the opposite number types. The forms also were designed to counterbalance problem order, because prior testing revealed that student performance tended to decline on problems near the end of the test.

Each form had twice as many story problems (4) as word equations (2) or symbol equations (2). The 32 story problems were used twice, once on eight forms in which the story problems came first and again on eight forms in which the story problems came last (in reverse order). The order of the word equations and equa- 


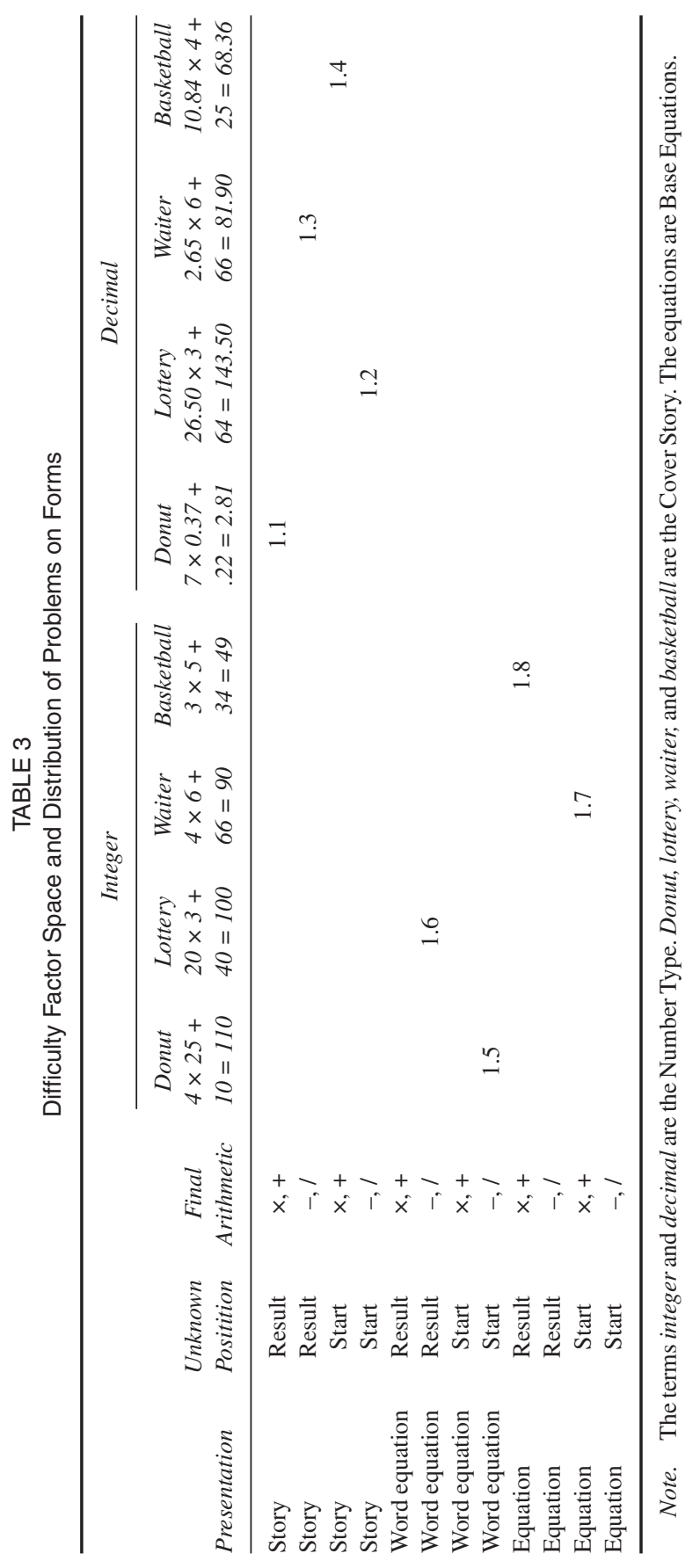


tions was also counterbalanced. The word equation and equation problems on the reversed forms were identical in their difficulty factor composition to their counterparts on the normal forms (i.e., each such pair had the same unknown position, number type, and final arithmetic), but differed in the base equation.

The form designs of DFA1 and DFA2 were identical with one exception. The base equation for the decimal Donut problems was changed on DFA2 from $7 \times .37$ $+.22=\mathbf{2 . 8 1}$ to $. \mathbf{3 7} \times 7+.22=\mathbf{2 . 8 1}$ so that, like all the other decimal-base equations, the answer to the unknown is always a decimal (e.g., .37 or 2.81) and not a whole number (e.g., 7).

Procedure. The quiz forms were given in class during a test day. Students were given 18 min to work on the quiz and were instructed to show their work, put a box around their final answer, and not to use calculators. We requested that students not use calculators so that we could better see students' thinking process in the arithmetic steps. The procedures for DFA1 and DFA2 were identical.

\section{Results for DFA1 and DFA2}

DFA1 results. We performed both an item analysis and subject analysis to assess whether the results generalize across both the item and student populations (cf. Clark, 1973). For the item analysis, we performed a three-factor ANOVA with items as the random effect and the three difficulty factors (representation, unknown position, and number type) as the fixed effects. ${ }^{3}$

We found evidence for main effects of all three factors. Students $(n=76)$ performed better on story problems $(66 \%)$ and word equations (62\%) than on equations $(43 \% ; F[2,108]=11.5, p<.001)$; better on result-unknown problems $(66 \%)$ than on start-unknown problems $(52 \% ; F[1,108]=10.7, p<.002)$; and better on whole-number problems $(72 \%)$ than on decimal-number problems $(46 \% ; F[1$, $108]=44, p<.001)$. A Scheffe's $S$ test post hoc showed a significant difference between story problems and equations $(p<.001)$ and word equations and equations $(p<.01)$, but not between story problems and word equations $(p=.80)$. None of the interactions was statistically significant.

These results contradict the symbolic facilitation hypothesis because story problems are not harder than equations. The results contradict the situation facilitation hypothesis because story problems are not easier than word equations. The results support the verbal facilitation hypothesis because word equations are sub-

\footnotetext{
${ }^{3}$ Because the dependent variable is a proportion (students solving the item correctly divided by the number of students who saw the item), we used a logit transformation as recommended by Cohen \& Cohen (1975, pp. 254-259): $.5 \times \ln (p /(1-p))$ where $p=0$ is replaced by $p=1 /(2 N)$ and $p=1$ by $p=$ $1-1 /(2 N)$ and $N$ is the number of students who see the item. Note, analyses using the proportions without transformation yield quite similar results and do not move any $p$ values across the 0.05 threshold.
} 
stantially easier than equations. In other words, the difference between verbal and symbolic representation, and not the difference between situational context and abstract description, accounts for the observed performance differences.

Figure 3 illustrates the main effects of the three difficulty factors: representation, unknown position, and number type. As is evident, the effect of representation is primarily a consequence of the difference between the symbolic equation representation and the two forms of verbal representation, story and word equations. There may be a difference between story and word equation representations for the decimal problems (see the graph on the right in Figure 3); however, the interaction between representation and number type is not statistically significant $(F[2,108]=.82, p=.44)$.

To confirm that the main effects of the three difficulty factors generalize not only across items but also across students (cf. Clark, 1972), we performed three separate one-factor repeated measure ANOVAs for each of the three difficulty factors: representation, unknown position, and number type. Unlike the item analysis above, the random effect here is students rather than items. Consistent with the item analysis, the repeated measures student analyses revealed significant main effects of each factor. Story and word problems are significantly easier than equations $(F[2,150]=8.35, p<.001)$. Result-unknowns are significantly easier than start-unknowns $(F[1,75]=19.8, p<.001)$. Whole-number problems are significantly easier than decimal-number problems $(F[1,75]=42.3, p<.001)$.

DFA2 results. The results of DFA2 replicate the major findings of DFA1 for the main effects of representation, unknown position, and number type (see Figure 4). Students $(n=171)$ were $67 \%$ correct on the whole number problems and only
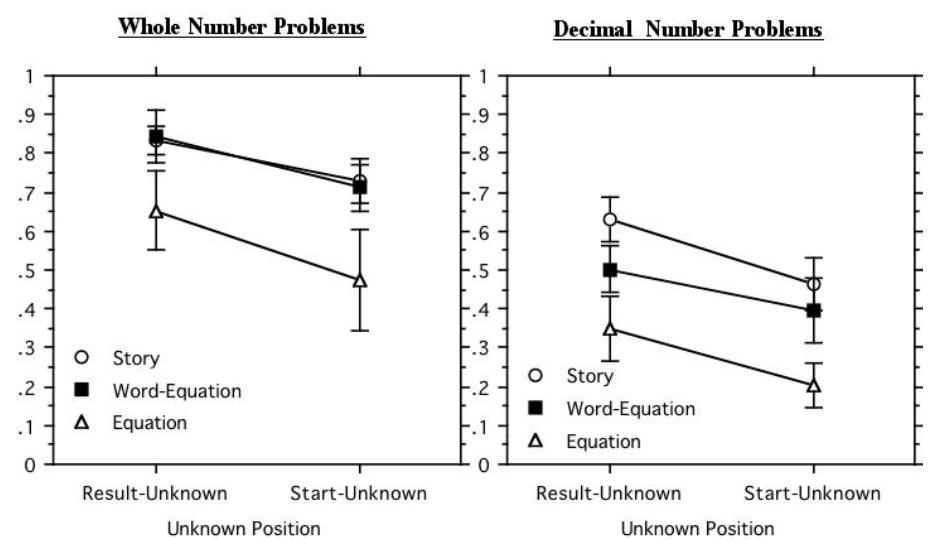

FIGURE 3 Proportion correct of high school algebra students in DFA1 $(n=76)$. The graphs show the effects of the three difficulty factors: representation, unknown position, and number type. The error bars display standard errors around the item means. 


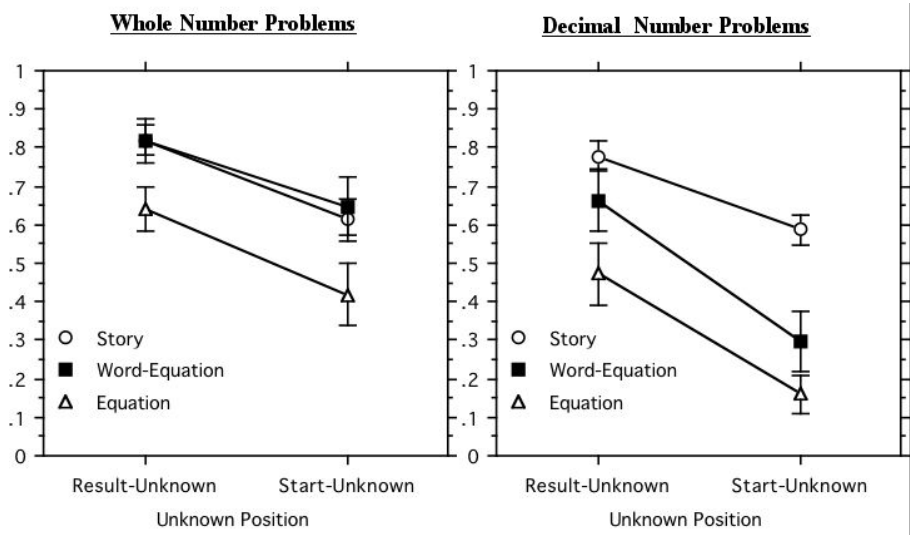

FIGURE 4 Proportion correct of high school algebra students in DFA2 $(n=171)$. The graphs show the effects of the three difficulty factors: representation, unknown position, and number type. The error bars display standard errors around the item means.

$54 \%$ correct on the decimal problems $(F[1,116]=22, p<.001)$. They were more often correct on result-unknown problems than start-unknown problems ( $72 \%$ vs. $49 \% ; F[1,116]=49, p<.001)$. As in DFA1, students performed best on story problems (70\%), next best on word equations (61\%), and substantially worse on equations $(42 \% ; F[2,116]=22, p<.001)$. Again, the big difference is between the word equations and equations ( $p<.001$ by a post hoc Scheffe's $\mathrm{S}$ test). Like DFA1, the difference between story problems and word equations is not statistically significant ( $p=.09$ by a post hoc Scheffe's $\mathrm{S}$ test). However unlike DFA1, there is a significant interaction between representation and number type $(F[2,116]=3.7, p$ $=.03$ ), as illustrated in Figure 4. When the number type is whole number, there is no difference between story and word equations (72\% vs. $73 \%)$. An advantage for story problems over word equations $(68 \%$ vs. $48 \%, p<01$ by a post hoc contrast test) appears only when the number type is decimal.

As seen in Figure 3, this interaction was apparent in DFA1 although it was not statistically significant. However, to further evaluate the situation facilitation hypothesis, we tested whether the advantage of story over word on decimal problems generalized across the two studies. The difference between the decimal story problems and decimal word equations is statistically reliable when the data from the two studies are combined ( $64 \%$ vs. $47 \%, p<.01$ by a post hoc Scheffe's $S$ test including only the decimal items). This result leads us to conclude that situation facilitation does exist but its scope is limited. In these data, problem-solving performance is only facilitated by the richer story contexts, above and beyond the more general verbal advantage, when decimal numbers are used. An explanation for this effect is proposed when we report findings of the strategy and error analyses in the next section. 
As in the student analysis in DFA1, a one-factor repeated measure ANOVA was conducted for each of the three difficulty factors with student as the random factor. The generalization of these effects across students was confirmed. Representation, unknown position, and number difficulty had statistically significant effects: $F(2,340)=37, p<.001 ; F(1,170)=137, p<.001$; and $F(1,170)=20, p$ $<.001$, respectively.

\section{STRATEGY AND ERROR ANALYSES OF LEARNERS}

To provide a cognitive process explanation of our results, we performed a detailed strategy and error analysis of student solution traces. This method serves as a qualitative analysis of students' written protocols. This analysis and the coding categories used were strongly influenced by cognitive modeling work within the ACT-R theory and production system (Anderson, 1993). The details of our ACT-R model of early algebra problem solving are beyond the scope of this article. We refer the interested reader to Koedinger \& MacLaren (2002).

\section{Qualitative Strategy Analysis-Stories Can Be Solved Without Equations}

The results of DFA1 and DFA2 contradict the common belief in the ubiquitous difficulty of story problems as well as the predictions of teachers and education researchers (Nathan \& Koedinger, 2000a) and cognitive researchers (Cummins et al., 1988). A common argument that supports this belief states that story problems are more difficult than matched equations because students must translate the story into an equation to solve it (Bobrow, 1968; Hawkes et al., 1929; Paige \& Simon, 1966). Indeed, we observed examples of this normative translation strategy in student solutions (see Figure 2a). However, we found many students using a variety of informal strategies as well (cf. Hall et al., 1989; Katz, Friedman, Bennett, \& Berger, 1996; Kieran, 1992; Resnick, 1987; Tabachneck, Koedinger, \& Nathan, 1994). By informal we mean that students do not rely on the use of mathematical (symbolic) formalisms, such as equations. We also mean that these strategies and representations are not acquired typically through formal classroom instruction. Figures $2 \mathrm{~b}$ through $2 \mathrm{~d}$ show examples of these informal strategies as observed in students' written solutions.

Figure $2 \mathrm{~b}$ shows the application of the guess-and-test strategy to a start-unknown word problem. In this strategy, students guess at the unknown value and then follow the arithmetic operators as described in the problem. They compare the outcome with the desired result from the problem statement; if the outcome differs, they try again. In the solution trace shown in Figure $2 b$, we do not know for sure 
where the student started writing-perhaps with the scribbled-out work on the right — but it is plausible that her first guess at "some number" was 2 . To the right and somewhat below the question mark at the end of the problem appears her written arithmetic applying the given operations multiply by .37 and add .22 to her guess of 2. The result is .96, which she sees is different than the desired result of 2.81 and perhaps also, that it is substantially lower than 2.81 . It appears her next guess is 5, which yields a result (2.07) that is closer but still too small. She abandons a guess of 6 , perhaps because she realizes that 2.07 is more than .37 short of 2.81. She tries 7 , which correctly yields 2.81 , and then writes, "The number is 7. " The guess-and-test strategy is not special to early algebra students, but also has been observed in the algebraic problem solving of college students (e.g., Hall et al., 1989; Katz et al., 1996; Tabachneck et al., 1994).

Figure $2 \mathrm{c}$ illustrates a second informal strategy for early algebra problem solving we call the unwind strategy. To find the unknown start value, the student reverses the process described in the problem. The student addresses the last operation first and inverts each operation to work backward to obtain the start value. In Figure 2c, the problem describes two arithmetic operations, subtract 64 and divide by 3 , in that order. The student starts (on the right) with the result value of 26.50 and multiplies it by 3; this inverts the division by 3 that was used to get to this value. Next, the student takes the intermediate result, 79.50, and adds 64.00, which inverts the subtraction by 64 described in the problem. This addition yields the unknown start value of 143.50 .

Although the informal guess-and-test strategy appears to be relatively inefficient compared with the formal translation strategy (compare the amount of writing in Figure 2b with 2a), the informal unwind strategy actually results in less written work than the translation strategy (compare 2c and 2a). In unwind, students go directly to the column arithmetic operations (see 2c) that also appear in translation solutions (see the column subtraction and division in 2a), but they do so mentally and save the effort of writing equations. (For other examples of such mental algebra among more expert problem solvers, see Hall et al., 1989; Tabachneck et al., 1994). The next section addresses whether students use informal strategies frequently and effectively.

\section{Quantitative Strategy Analysis-Words Elicit More Effective Strategies}

We coded student solutions for the strategies apparent in their written solutions for DFA1 and DFA2. Our strategy analysis focuses on the early algebra start-unknown problems (shown in Figures 2a-2d). We observed little variability in students' strategies on the result-unknown problems. Although some students translated verbal result-unknown problems into equations (see Figure 2e), in the majority of 
solutions students went directly to the arithmetic. Typical solution traces included only arithmetic work, as illustrated in the lower left corner of Figure 2e (i.e., all but the three equations).

Table 4 shows the proportion of strategy use on start-unknown problems for the three representations. Different representations elicited different patterns of strategy usage. Story problems elicited the unwind strategy most often $(50 \%$ of the time). Story problems seldom elicited the symbolic translation strategy typically associated with algebra (only $5 \%$ of the time). Situationless word equations tended to elicit either the guess-and-test (23\% of the time) or unwind (22\%) strategy. Equations resulted in no response $32 \%$ of the time, more than twice as often as the other representations. When students did respond, they tended to stay within the mathematical formalism and apply symbol manipulation methods (22\%). Even on equations, students used the informal guess-and-test (14\%) and unwind (13\%) strategies fairly often. In fact, as Figure $2 d$ illustrates, sometimes students translated a verbal problem to an equation but then solved the equation subproblem informally, in this case, using the unwind strategy.

Story problems may elicit more use of the unwind strategy than word equations because of their more episodic or situated nature (cf. Hall et al., 1989). Retrieving real-world knowledge, for example, about a box of donuts (see Figure 1) may support students in making the whole-part inference (cf. Greeno, 1983; Koedinger \& Anderson, 1990) that subtracting the box cost from the total cost gets one closer to the solution.

We also saw that word equations elicited more unwind strategy usage than equations. Although word equations are situationless, we did use words such as starting with, and then, and I get that describe someone performing an active procedure. Even the mathematical operators were described as actions (multiply and $a d d$ ) instead of as relations (times and plus). Perhaps this active description made it easier for students to think of reversing the performance of the procedure described. We suggest future research that tests this action facilitation hypothesis and contrasts our current procedural word equations with relational word equations such as "some number times .37 plus .22 equals 2.81" (see Figure 1 for the analogous procedural word equation). Action facilitation predicts better student

TABLE 4

Solution Strategies (Percentages) Employed by Solvers as a Function of Problem Representation for Start-Unknown Problems

\begin{tabular}{lccccccr}
\hline $\begin{array}{l}\text { Problem } \\
\text { Representation }\end{array}$ & Unwind & $\begin{array}{c}\text { Guess and } \\
\text { Test }\end{array}$ & $\begin{array}{c}\text { Symbol } \\
\text { Manipulation }\end{array}$ & $\begin{array}{c}\text { No } \\
\text { Response }\end{array}$ & $\begin{array}{c}\text { Answer } \\
\text { Only }\end{array}$ & Unknown & Total \\
\hline Story & $\mathbf{5 0}$ & 7 & 5 & 12 & 18 & 8 & 100 \\
Word equation & $\mathbf{2 2}$ & $\mathbf{2 3}$ & 11 & 13 & 19 & 12 & 100 \\
Equation & 13 & 14 & $\mathbf{2 2}$ & $\mathbf{3 2}$ & 11 & 8 & 100 \\
\hline
\end{tabular}


performance on procedural than relational word equations whereas verbal facilitation predicts equal performance (with both better than equations).

In addition to investigating differences in strategy selection, we also analyzed the effectiveness of these strategies. Table 5 shows effectiveness statistics (percent correct) for the unwind, guess-and-test, and symbol manipulation strategies on start-unknown problems in all three representations. The informal strategies, unwind and guess-and-test, showed a higher likelihood of success $(69 \%$ and $71 \%$, respectively) than did use of the symbol manipulation approach $(51 \%)$. It appears that one reason these algebra students did better on story and word problems than on equations is that they selected more effective strategies more often. However, this effect could result from students' choosing informal strategies on easier problems. Use of a no-choice strategy selection paradigm (Siegler \& Lemaire, 1997) is a better way to test the efficacy of these strategies. Nhouyvanisvong (1999) used this approach to compare equation solving and guess-and-test performance on story problems normatively solved using a system of two equations or inequalities. Surprisingly, he found students instructed to use guess-and-test were more successful than those instructed to use equation solving.

\section{Error Analysis-Comprehending Equations Is Harder Than Comprehending Words}

Our analysis of student strategies, particularly the differential use of informal strategies, provides one reason why story and word problems can be easier than matched equations. Our analysis of student errors provides a second reason. Unlike the first- and second-grade students in Cummins et al. (1988), who had yet to acquire critical English-language comprehension skills, high school algebra students had more developed English comprehension skills, but were still struggling to acquire critical algebra-language comprehension skills.

\section{TABLE 5}

Likelihood That Strategies Used by Students on Start-Unknown Problems Leads to a Correct Answer

\begin{tabular}{lcc}
\hline Strategies & No. Correct/No. Attempted & Likelihood Strategy Leads to Correct Answer \\
\hline Unwind & $232 / 335$ & $69 \%$ \\
Guess and test & $89 / 125$ & $71 \%$ \\
Symbol manipulation & $56 / 109$ & $51 \%$ \\
Answer only & $90 / 161$ & $56 \%$ \\
Unknown & $38 / 89$ & $43 \%$ \\
Total with response & $505 / 819$ & $62 \%$ \\
No response & $0 / 169$ & $0 \%$ \\
Total & $505 / 988$ & $51 \%$ \\
\hline
\end{tabular}


Categorization of student errors into three broad categories-(a) no response, (b) arithmetic error, and (c) other conceptual errors-provides insight into how students process story problems and equations differently. Students' solutions were coded as no response if nothing was written down for that problem. Systematic occurrences of no-response errors suggested student difficulties in comprehending the external problem representation. Our counterbalancing for the order of problem presentation allowed us to rule out student fatigue or time constraints. Student solutions were coded as arithmetic error if a mistake was made in performing an arithmetic operation but the solution was otherwise correct (e.g., Figure 5f). Arithmetic errors indicated correct comprehension and, in the case of start-unknowns, correct formal or informal algebraic reasoning. Apart from some rare (19 errors out of 1,976 solutions) nonarithmetic slips, such as incorrectly copying a digit from the problem statement, all other errors were coded as conceptual errors. Examples of a variety of different conceptual errors are shown in Figures 5a through 5e.

Figure 6a shows the proportions of the error types for the three levels of the representation factor: story, word equation, or equation. The key difference between equations and the two verbal representations (story, word equation) is accounted for primarily by no response errors $(26 \%=127 / 492$ vs. $8 \%=119 / 1,465)$. No-response errors imply difficulty comprehending the external problem representation. These data suggest that students in these samples were particularly challenged by the demands of comprehending the symbolic algebra representation. The language of symbolic algebra presents new demands that are not common in English or in the simpler symbolic arithmetic language of students' past experience (e.g., one-operator number sentences, such as $6-2=$ ?, used in Cummins et al., 1988). The algebraic language adds new lexical items, such as $x, *, /$, , and new syntactic and semantic rules, such as identifying sides of an equation, interpreting the equal sign as a relation rather than as an operation, order of arguments, and order of operators. When faced with an equation to solve, students lacking aspects of algebraic comprehension knowledge may give up before writing anything down.

Further evidence of students' difficulties with the "foreign language of algebra" comes from students' conceptual errors. As shown in Figure 5a, students make more conceptual errors on equations $(28 \%=103 / 365)$ than on word equations $(23 \%=103 / 450)$ and particularly story problems $(16 \%=144 / 896) .{ }^{4}$ Figures $6 \mathrm{a}$ and $6 \mathrm{~b}$ show examples of conceptual errors on equations. Figure $6 \mathrm{a}$ shows an order-of-operations error whereby the student performs the addition on the left-hand side $(.37+.22)$, which violates the operator precedence rule that multiplication should precede addition. We found a substantial proportion of order-of-operation errors on equations $(4.9 \%=24 / 492)$, while order-of-operations errors on verbal problems were extremely rare $(0.3 \%=4 / 1,468)$.

\footnotetext{
${ }^{4}$ The proportion of conceptual errors reported here is conditional on there having been a response — solutions with no response errors are not counted in the denominator.
} 


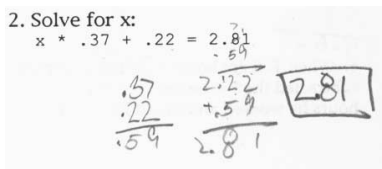

a. Order of operations error. Student inappropriately adds .37 and .22 .
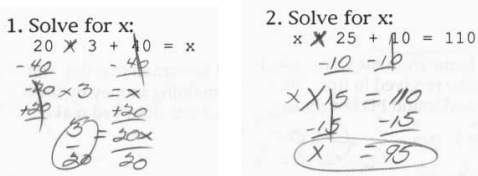

b. Algebra manipulation errors. Student subtracts from both sides of the plus sign rather than both sides of the equal sign.

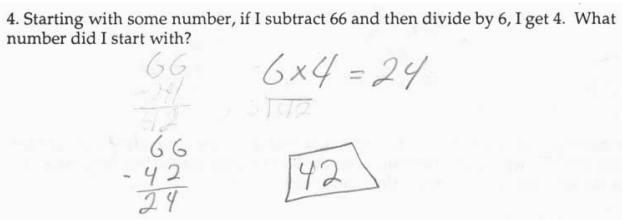

c. Argument order error . Student treats "subtract 66" $(\mathrm{x}-66)$ as if it were "subtract from

$$
66 "(66-x) \text {. }
$$
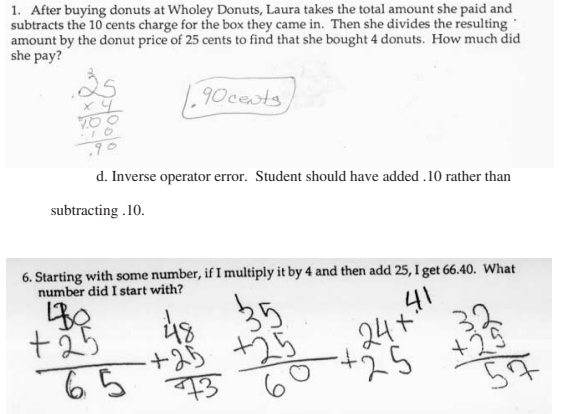

e. Incomplete guess-and-test error. Student gives up before finding a guess that works.

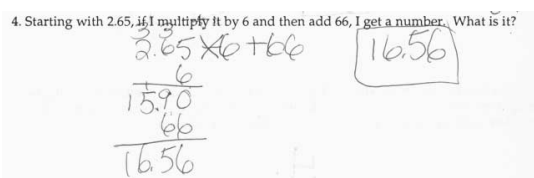

f. Decimal alignment arithmetic error. Student adds 66 to .90 aligning flush right rathe than aligning place values or the decimal point.

FIGURE 5 Examples of errors made by students: (a) order of operations, (b) algebra manipulation, (c) argument order, (d) inverse operator, (e) incomplete guess-and-test, (f) decimal alignment arithmetic error. 

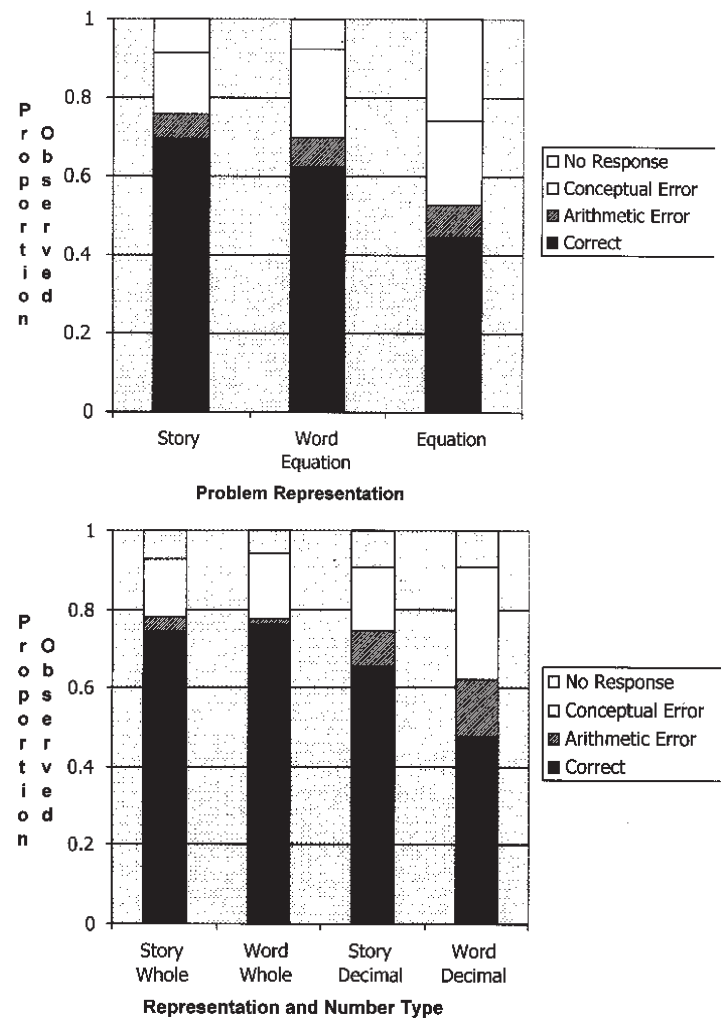

FIGURE 6 Frequency of broad error categories helps to explain the causes of the verbal and situation facilitation effects observed: (a) proportions of correct and incorrect responses for story, word equations, and equations. A verbal facilitation effect is indicated particularly in the fewer no-response errors in the story and word equation problems;(b) proportions of correct and incorrect responses for story versus word equations crossed with whole versus decimal number problems. A situation facilitation effect is indicated in decimal problems with fewer conceptual and arithmetic errors on story decimal problems than word equation decimal problems.

Figure $6 \mathrm{~b}$ shows two examples of algebra manipulation errors. This student appears to have some partial knowledge of equation solving, namely, that you need to get rid of numbers by performing the same operation to both sides of the equation. The student, however, operated on both sides of the plus sign rather than both sides of the equal sign. These errors indicate a lack of comprehension of the quantitative structure expressed in the given equations. Such errors appear less frequently on word and story problems, indicating that comprehension of the quantitative structure is easier for students when that structure is expressed in English words rather than in algebraic symbols. 
Explaining situation facilitation. Algebraic language acquisition difficulties, such as comprehension and conceptualization of the underlying quantitative relations, account for much of the error difference between equations and verbal problems. These differences are consistent with the verbal facilitation hypothesis. However, we also observed a smaller situation facilitation effect whereby story performance was better than word equation performance under certain conditions-namely when dealing with decimal numbers. This interaction was statistically reliable in DFA2, but the same trend also was apparent in the smaller DFA1 data set. Figure $6 \mathrm{~b}$ shows the proportions of the three error types for the representation and number-type factors together. The interaction between representation and number type is caused largely by fewer arithmetic errors on decimal story problems $(12 \%=46 / 389$ on decimal vs. $5 \%=17 / 363$ on whole) than for word equations or equations $(23 \%=33 / 144$ on decimal vs. $2 \%=4 / 203$ on whole $) .{ }^{5}$ Misalignment of place values in decimal arithmetic (see Figure $5 \mathrm{f}$ ) was a common error on situationless word and equation problems. In contrast, this error was rare on story problems. The money context of the story problems appears to have helped students correctly add (or subtract) dollars to dollars and cents to cents. In contrast, without the situational context (in word equations and equations), students would sometimes, in effect, add dollars to cents.

Situation-induced strategy differences also appear to contribute to students' somewhat better performance on story problems than on word equations. As we saw from the strategy analysis, students were more likely to use the unwind strategy on story problems $(50 \%)$ than on word equations (22\%) or equations (13\%). The unwind strategy may be less susceptible to conceptual errors than the guess-and-test strategy, which was used more frequently on word equations. A particular weakness of the guess-and-test strategy is the need to iterate through guesses until a value is found that satisfies the problem constraints. As illustrated in Figure 6e, a common conceptual error in applying guess-and-test is to give up before a satisfactory value is found. Guess-and-test is more difficult when the answer is a decimal rather than a whole number because this strategy takes more iterations in general to converge on the solution. This weakness of guess-and-test and the strategy's greater relative use on word equations than on story problems may account for the greater number of conceptual errors on decimal word equations than on decimal story problems (Figure $6 b$ ).

\footnotetext{
${ }^{5}$ The proportion of arithmetic errors reported here is conditional on the solution being conceptually correct-solutions with no response or conceptual errors are not counted in the denominator.
} 


\section{DISCUSSION}

\section{Assessing the Symbolic, Situation, and Verbal Facilitation Hypotheses}

In the introduction, we contrasted three hypotheses regarding the effects of different problem representations on algebra problem solving. The symbolic facilitation hypothesis predicts that story problems are more difficult than matched equations because equations are more parsimonious and their comprehension more transparent. Our results with high school students solving entry-level algebra problems in two samples contradict this claim and show, instead, that symbolic problems can be more difficult for students, even after a year or more of formal algebra instruction.

Alternatively, the situation facilitation hypothesis follows from situated cognition research (Baranes et al., 1989; Brown, Collins, \& Duguid, 1989; Carraher et al., 1987; Nunes et al., 1993) and suggests that problem situations facilitate student problem solving by contextualizing the quantitative relations. The prediction of the situation facilitation hypothesis, that story problems are easier than both word equations and equations, is not fully consistent with our results. Although students in DFA1 and DFA2 did perform better on story problems than on equations, they also performed better on word equations than on equations. Thus, it is not simply the situated nature of story contexts that accounts for better performance.

The verbal facilitation hypothesis focuses not on the situated nature of story problems per se but on their representation in familiar natural language. The hypothesis follows from the idea that students, even after an algebra course, have had greater experience with verbal descriptions of quantitative constraints than with algebraic descriptions of quantitative constraints. Thus, it predicts that word equations, as well as story problems, will be easier than mathematically equivalent equations. The prediction relies on two claims. First, students initially have more reliable comprehension knowledge for verbal representations than symbolical ones. Second, verbal representations better cue students' existing understanding of quantitative constraints and, in turn, informal strategies or weak methods for constraint satisfaction, such as guess-and-test or working backwards. Early algebra students appear better able to successfully use such strategies rather than the symbol-mediated equation-solving strategy.

This second claim, that verbal representations help cue students' knowledge, is consistent with the assertion made by Nunes et al. (1993, p. 45) that "discrepant performances can be explained in terms of the symbolic systems being used." They found evidence that the chosen symbolic system (e.g., formal vs. verbal or oral) determines performance more than the given one. Students performed better on all kinds of problems, whether abstract or situational, when they used informal oral strategies than when they used formal written strategies. Our strategy analysis revealed analogous results for older students and a different class of problems. In ad- 
dition to providing further evidence to support the explanation provided by Nunes et al. (1993), our results extend that explanation. In our error analysis, we found evidence that the given representation has direct effects on student performance beyond its indirect effects on influencing student strategy choice. More students failed to comprehend given equation representations than given verbal representations, as indicated by a greater frequency of no-response and conceptual errors on the former (as illustrated in Figure 6a).

Like Baranes et al. (1989), we did see some localized situational facilitation in students' performance on story problems. First, students used the unwind strategy more often on story problems than on word equations or symbolic equations. Because this strategy is more reliable than equation manipulation and more efficient than guess-and-test, students were less likely to make conceptual errors when solving decimal story problems. A second situational effect involves support for decimal alignment in the context of a story problem. Students avoided adding dollars to cents in the story context and thus made fewer arithmetic errors on problems involving decimals in this context than in context-free word equations and equations.

One might interpret some educational innovations emphasizing story contexts (e.g., Cognition and Technology Group at Vanderbilt, 1997; Koedinger, Anderson, Hadley, \& Mark, 1997), calls for mathematics reform (e.g., National Council of Teachers of Mathematics, 2000), and situated cognition and ethnomathematical research (e.g., Brown et al., 1989; Cognition and Technology Group at Vanderbilt, 1990; Greeno \& MMAP Group, 1998; Roth, 1996) as suggesting that "authentic" problem situations generally help students make sense of mathematics. In contrast, our results are consistent with those of Baranes et al. (1989) that situational effects are specific and knowledge related. Similarly, Nunes et al. (1993, p. 47) argued that the differences they observed "cannot be explained only by social-interactional factors." Indeed, as long as problems were presented in a story context, they found no significant difference between performances in different social interaction settings, whether a customer-vendor street interaction or a teacher-pupil school interaction.

Situational effects are not panaceas for students' mathematical understanding and learning. Clearly, though, problem representations, including their embedding and referent situations, have significant effects on how students think and learn. Better understanding of these specific effects should yield better instruction.

Two reasons why story and word problems can be easier. Two key reasons explain the surprising difficulty of symbolic equations relative to both word and story problems. These two reasons correspond, respectively, to the solution and comprehension phases of problem solving illustrated in Figure 1. First, students' access to informal strategies for solving early algebra problems provides an alternative to the logic that word problems must be more difficult because equations are needed to solve them. Our data, as well as that of others (cf. Hall et al., 1989; Stern, 1997), demonstrates that solvers do not always use equations to solve 
story problems. Second, despite the apparent ease for experienced mathematicians of solving symbolic expressions, the successful manipulation of symbols requires extensive symbolic comprehension skills. These skills are acquired over time through substantial learning. Early in the learning process, symbolic sentences are like a foreign language - students must acquire the implicit processing knowledge of equation syntax and semantics. Early algebra students' weak symbolic comprehension skills contrast with their existing skills for comprehending and manipulating quantitative constraints written in English. When problems are presented in a language students understand, students can draw on prior knowledge and intuitive strategies to analyze and solve these problems despite lacking strong knowledge of formal solution procedures.

One dramatic characterization of our results is that under certain circumstances students can do as well on simple algebra problems as they do on arithmetic problems. This occurs when the algebra problems are presented verbally $(59 \%$ and $60 \%$ correct on start-unknown stories in DFA1 and DFA2) and the arithmetic problems are presented symbolically (51\% and 56\% correct on result-unknown equations in DFA1 and DFA2). Although we have been critical of the sweeping claim made by Cummins and colleagues (1988) that "students ... continue to find word problems ... more difficult to solve than problems presented in symbolic format (e.g., algebraic equations)," we agree on the importance of linguistic development. However, we broaden the notion of linguistic forms to include mathematical symbol sentences. Cummins emphasized that the difficulty in story problem solving is not specific to the solution process, but is also in the comprehension process. "The linguistic development view holds that certain word problems are difficult to solve because they employ linguistic forms that do not readily map onto children's existing conceptual knowledge structures." (Cummins et al, 1988, p. 407). Our results indicate that the difficulty in equation solving similarly is found not only in the solution process, but also in the comprehension process. Algebra equations employ linguistic forms that beginning algebra students have difficulty mapping onto existing conceptual knowledge structures.

Although our results are closer to those studies that have found advantages for story problems over symbolic problems under some circumstances (Baranes et al, 1989; Carraher et al., 1987), our analysis of the underlying processes has important differences. Like the situated cognition researchers, we found particular circumstances in which the problem situation facilitated performance (money and decimal arithmetic). However, our design and error analysis focused not only on when and why story problems might be easier, but also on when and why equations might be harder. The key result here is that equations can be more difficult to comprehend than analogous word problems, even though both forms have no situational context. Kirshner (1989) and Sleeman (1984) have also highlighted the subtle complexities of comprehending symbolic equations and Heffernan \& Koedinger (1998) have identified similar difficulties in the production of symbolic equations. 


\section{Logical Task-Structure Versus Experience-Based Reasons for Difficulty Differences}

An important question regarding these results is whether difficulty factor differences are a logical consequence of the task structure or a consequence of biases in experience as determined by cultural practices (e.g., presenting students with algebraic symbolism later, as in the United States, versus early, as in Russia and Singapore). The cognitive modeling work we have done (Koedinger \& MacLaren, 2002) has led to the observation that some difficulty factors are a fixed consequence of task structure, whereas others are experience based.

The greater difficulty of start-unknown problems over result-unknown problems is a logical consequence of differences in task structure. When students solve a start-unknown problem, they must do everything they need to do to solve an otherwise equivalent result-unknown problem (e.g., comprehend the problem statement, perform arithmetic operations) in addition to dealing with the fact that the arithmetic operations cannot be simply applied as described in the problem. Thus, start-unknown problems are logically constrained to be at least as difficult as result-unknown problems.

In contrast, the difficulty difference between word problems and equations is not logically constrained. Although there is some overlap in the knowledge required to solve word problems and equations (e.g., arithmetic and operator inversion or guess-and-test skills), each problem category requires some knowledge that the other does not. Word problems require knowledge for verbal comprehension not needed for equations, and equations require knowledge for comprehending symbolic notation not needed for word problems. Thus, the difficulty difference between these problem categories is not fixed but depends on students' relative experience with verbal and symbolic representations.

The proportion of a student's exposure to quantitative constraints in verbal versus symbolic form may depend, in turn, on cultural factors. Given the prevalence of natural language for other communicative needs, early algebra students are likely to have more reliable knowledge for comprehending verbal descriptions than symbolic ones. Thus, students may tend to find comprehending word problems easier than comprehending equations, at least initially. However, in an educational culture where symbolic algebra representations are experienced earlier and more frequently by students, we would expect the difference to shrink over time. In contrast to the approach in traditional U.S. curricula of introducing start-unknown number sentences using boxes or blanks (e.g., __ $+5=8$ ) to represent unknowns, students in other countries (Russia, Singapore) are introduced to the use of letters (e.g., $x+5=8$ ) to represent unknowns in the elementary grades (e.g., Singapore Ministry of Education, 1999). If our study was replicated in such countries, we expect that students would not experience the kind of equation comprehension difficulties observed here and 
thus may show as good or better performance on symbolic equations relative to story problems. Perhaps future cross-cultural research can test this prediction.

\section{Instructional Implications}

Some advantages and disadvantages of four alternative instructional strategies might appear to follow from our results. First, to the extent that people can effectively solve problems without symbolic equations, why are algebra equations and equation-solving skills needed at all? One reason is that algebraic symbolism has uses outside of problem solving, including efficiently communicating formulas and facilitating theorem proving. Even within problem solving, equations may well facilitate performance for more complex problem conditions (Koedinger et al., submitted; Verzoni \& Koedinger, 1997). Replacing algebra equations with alternative representations is an intriguing idea (cf. Cheng, 1999; Koedinger \& Terao, 2002), but we do not advocate eliminating equations and equation solving from the curriculum.

Because equation solving is so hard for students to learn and because it is important, a second instructional strategy worth considering is a mastery-based approach (Bloom, 1984) that focuses on equation-solving instruction in isolation. This strategy targets the syntax of algebraic transformation rules and does not address algebraic symbolism as a representational language with semantics. Instruction that isolates transformational rules may reduce cognitive load and thus facilitate learning (Sweller, 1988). However, practicing procedures without an understanding of underlying principles often leads to fragile knowledge that does not transfer well (Judd, 1908; Katona, 1940). To be sure, students often make errors in equation solving that clearly violate the underlying semantics (Figures 5a-5b; Payne \& Squibb, 1990).

A third alternative takes a developmental view and suggests starting with instructional activities involving story problems, which are easier for students to solve, and moving later to more abstract word equation problems and then to symbolic equations. In this view, decomposing instruction to focus on difficult equation-solving skills is fine. However, such instruction should come after students have learned the meaning of algebraic sentences, that is, after they have learned to translate back and forth between English and algebra. This progressive formalization sequencing (Romberg \& de Lange, in press) is unlike many current textbooks that teach equation solving before analogous story problem solving (Nathan et al., 2002). Our theoretical analysis (Koedinger \& MacLaren, 2002) and experiments with simulated students (MacLaren \& Koedinger, 2002) support the hypothesis that developing students' understanding of quantitative constraints in the verbal representation should facilitate learning of the symbolic representation of quantitative constraints.

The fourth instructional alternative advocates that students develop some competence at encoding and representing constraints in verbal form prior 
to- and as the basis for-equation-solving instruction. Here, students' understanding of verbal constraints is used as a bridge for understanding and manipulating symbolic constraints. Activities and exercises should focus on translating back and forth between verbal and symbolic representations. According to this view, instruction should aid students in making explicit connections between their existing verbal knowledge and the new symbolic knowledge they are learning. In this approach, instruction aims to help students to understand the meaning of algebraic sentences and symbol-manipulation procedures by grounding symbolic forms in students' preexisting verbal comprehension and strategic competence. Relevant grounding activities might include (a) matching equations and equivalent word equations, (b) translating equations to story problems and solving both, (c) solving story problems and summarizing both the story and the solution in equations, and (d) making students aware of the algorithmic nature of their intuitive verbal strategies and generalizing these procedures to include symbolic formalisms. We have some indication that this approach is effective for teaching sixth graders to solve story and word equations first informally and then symbolically (Nathan \& Koedinger, 2000c). We also have begun to experimentally compare this approach to other approaches in extended interventions with seventh- and eighth-grade students (Nathan, Stephens, Masarik, Alibali, \& Koedinger, 2002).

Grounding new representations to familiar representations has the potential to promote reliable performance by facilitating meaning-making and self-monitoring processes. For example, solution steps generated in the abstract equation representation can be checked against the results of reasoning with a concrete story representation. Errors in use of the equation representation may be detected and fixed through comparison with the analogous story solution. Further, steps in story solutions can be used as examples to learn, via analogy, transformations in the equation representation. Instruction that focuses on bridging permits use of fallback strategies that can help students to acquire and debug new, more powerful abstract knowledge.

Some prior studies have indicated the promise of bridging instruction in algebra learning. Nathan et al. (1992) demonstrated that student learning of algebraic symbolization for multiple-unknown problems (e.g., translating more complex story problems into equations such as $12[t-2]+8 t=76$ ) was enhanced by encouraging students to coordinate between a grounded representation, in this case an animation of the problem situation, and the abstract symbolic representation. Koedinger and Anderson (1990) demonstrated that student learning of algebra symbolization for simpler linear start-unknowns (e.g., translating story problems into expressions such as $42 x+35$ ) was enhanced by having students first solve story problems and then use the emergent arithmetic procedure essentially to induce an algebraic expression. In more applied work, a key feature of the Cognitive Tutor Algebra curriculum and software (Koedinger, Anderson, Hadley, \& Mark, 1997) is to help stu- 
dents learn more abstract algebraic representations (e.g., symbols and graphs) by bridging off existing knowledge in more grounded representations (e.g., situations, words, and tables of values). Classroom field studies have demonstrated that Cognitive Tutor Algebra results in dramatic improvements in student achievement relative to traditional algebra curricula (Koedinger et al., 1997). Brenner et al.(1997) demonstrated the effectiveness of a similar approach that employed multiple representations in supporting algebra learning.

\section{CONCLUSION}

Studies in a variety of domains have shown that "different presentation formats elicit qualitatively different solution strategies" (Mayer, 1982a, p. 448) and can lead to dramatically different performance (Kotovsky, Hayes, \& Simon, 1985; Zhang \& Norman, 1994). We have identified two ways in which external representations can change performance. First, performance may change because one external representation is more difficult to comprehend than another. Second, performance can change because different external representations may be comprehended in different ways and in turn cue different processing strategies.

We have found it useful to think of the process of learning formal representations (e.g., algebra, vectors, chemical equations, etc.) as a kind of foreign-language learning. Students acquire some explicit knowledge of the grammar of algebra, such as what a term or a factor is. However, it is likely that much of the knowledge of parsing algebraic equations is perceptual learning of "chunks" (cf. Servan-Schreiber \& Anderson, 1990) that implicitly characterize the syntactic structure of expressions and equations (cf. Berry \& Dienes, 1993; Kirshner, 1989; Reber, 1967). Students may also acquire some explicit knowledge of semantic mappings of grammatical structures, such as precedence rules for order of operations. However, just as at the syntactic level, we believe substantial implicit knowledge is acquired at the semantic and pragmatic levels. For instance, Alibali and Goldin-Meadow (1993) have shown that when students are first learning to solve problems such as $3+4+5=\ldots+5$, they often have implicit knowledge of alternative hypotheses for meaning of the equal sign that are independently revealed in speech and gesture. A student solving this problem may simultaneously speak in accord with one hypothesis ("=" means one must give an answer and say 12 or 17) yet gesture (pointing at the 5 on both sides) in accord with another ("=" means balance).

To the extent that fluency with mathematical symbols is acquired largely through implicit learning processes (Berry \& Dienes, 1993; Reber, 1967), those who have developed such expertise cannot easily and directly reflect on the difficulties learners must overcome. This observation is consistent with Nathan \& Koedinger's (2000a, 2000b) survey results that algebra teachers and educators typically judge equations to be easier than matched story and word problems, 
contrary to the results reported here. As we gain expertise in concise symbolic languages such as equations, it feels as though we can transparently understand and solve them, as one teacher said, "without thinking." It is tempting to project this ease onto students and not recognize the difficulties learners experience in learning to comprehend and use mathematical symbols (e.g., Figures 5a and 5b). At the same time, our expertise and corresponding awareness of the formal method for solving a problem (e.g., Figure 2a) can lead us to underestimate the informal understandings and strategies (e.g., Figures $2 b$ and $2 c$ ) that students may bring to a content domain.

We have coined the phrase expert blind spot to refer to this tendency, on one hand, to overestimate the ease of acquiring formal representation languages, and on the other hand, to underestimate students' informal understandings and strategies (Koedinger \& Nathan, 1997; Nathan, Koedinger, \& Alibali, 2001). Expert blind spot has clear consequences for the design and delivery of instruction. Teachers or textbook writers cannot effectively provide instruction that builds on students' prior knowledge (Bransford, Brown, \& Cocking, 1999) if they employ incorrect assumptions about what incoming students know, what activities are particularly difficult, and what activities elicit informal understandings.

Methods of cognitive task analysis, such as the difficulty factors assessment and the fine-grained analyses of students' strategies and errors used in these studies, can help to develop detailed theories of learner knowledge, implicit and explicit, and how external representations and activities evoke that knowledge. Such research is an important activity for the learning sciences because much of educational decision making may be incorrectly biased by explicit knowledge and beliefs that are at odds with the reality of student thinking and learning.

\section{ACKNOWLEDGMENTS}

This research was supported by Grant JSMF 95-11 from the James S. McDonnell Foundation, Cognitive Studies in Education Practice.

We acknowledge the contributions of Hermi Tabachneck, who participated in early design and analysis, and Ben MacLaren, who did the solution coding. We also thank Martha Alibali, Lisa Haverty, and Heather McQuaid for reading and commenting on drafts; and Allan Collins, Andee Rubin, and an anonymous reviewer for their helpful comments.

\section{REFERENCES}

Alibali, M. W., \& Goldin-Meadow, S. (1993). Transitions in learning: What the hands reveal about a child's state of mind. Cognitive Psychology, 25, 468-523. 
Anderson, J. R. (1993). Rules of the mind. Hillsdale, NJ: Lawrence Erlbaum Associates, Inc.

Baranes, R., Perry, M., and Stigler, J. W. (1989). Activation of real-world knowledge in the solution of word problems. Cognition and Instruction, 6, 287-318.

Bednarz, N., \& Janvier, B. (1996). Emergence and development of algebra as a problem-solving tool: Continuities and discontinuities with arithmetic. In N. Bednarz, C. Kieran, \& L. Lee (Eds.), Approaches to algebra: Perspectives for research and teaching. Dordrecht, Holland: Kluwer Academic.

Bednarz, N., Kieran, C., \& Lee, L. (1996). Approaches to Algebra: Perspectives for Research and Teaching. Dordrecht, Holland: Kluwer Academic.

Berry, D. C., \& Dienes, Z. (1993). Implicit learning: Theoretical and empirical issues. Hove, England: Lawrence Erlbaum Associates, Inc.

Bloom, B.S. (1984). The 2-sigma problem: The search for methods of group instruction as effective as one-to-one tutoring. Educational Researcher, 13, 4-16.

Bobrow, D. G. (1968). Natural language input for a computer problem-solving system. In M. Minsky (Ed.), Semantic information processing (pp. 135-215). Cambridge, MA: MIT Press.

Bransford, J. D., Brown, A. L., \& Cocking, R. R. (1999). How people learn: Brain, mind, experience and school. Washington, DC: National Academy Press.

Brenner, M. E., Mayer, R. E., Moseley, B., Brar, T., Duran, R., Reed, B. S., et al. (1997). Learning by understanding: The role of multiple representations in learning algebra. American Educational Research Journal, 34(4), 663-689.

Briars, D. J., \& Larkin, J. H. (1984). An integrated model of skill in solving elementary word problems. Cognition and Instruction, 1, 245-296.

Brown, J. S., Collins, A., \& Duguid, P. (1989). Situated cognition and the culture of learning. Educational Researcher, 18(1), 32-41.

Carpenter, T. P., Kepner, H. S., Corbitt, M. K., Lindquist, M. M., \& Reys, R. E. (1980). Solving verbal problems: Results and implications for National Assessment. Arithmetic Teacher, 28, 8-12.

Carpenter, T. P., \& Levi, L. (1999, April). Developing conceptions of algebraic reasoning in the primary grades. Paper presented at the annual meeting of the American Educational Research Association, Montreal, Canada.

Carpenter, T. P., \& Moser, J. M. (1984). The acquisition of addition and subtraction concepts in grades one through three. Journal for Research in Mathematics Education, 15, 179-202.

Carraher, T. N., Carraher, D. W., \& Schliemann, A. D. (1987). Written and oral mathematics. Journal for Research in Mathematics Education, 18, 83-97.

Carraher, D. W., Schliemann, A. D., and Brizuela, B. M. (2000, July). Bringing out the algebraic character of arithmetic. Paper presented at the 24th annual Psychology of Mathematics Education (PME) Conference, Hiroshima, Japan.

Cheng, P. C.-H. (1999). Interactive law encoding diagrams for learning and instruction. Learning and Instruction. 9(4), 309-326.

Clark, H. H. (1973). The language-as-fixed-effect fallacy: A critique of language statistics in psychological research. Journal of Verbal Learning and Verbal Behavior, 12, 334-359.

Clement, J. (1982). Algebra word problem solutions: Thought processes underlying a common misconception. Journal for Research in Mathematics Education, 13, 16-30.

Cognition and Technology Group at Vanderbilt (1990). Anchored instruction and its relationship to situated cognition. Educational Researcher, 19(6), 2-10.

Cognition and Technology Group at Vanderbilt (1997). The Jasper Project Lessons in curriculum, instruction, assessment, and professional development. Mahwah, NJ: Lawrence Erlbaum Associates, Inc.

Cohen, J., \& Cohen, P. (1975). Applied Multiple Regression/Correlation Analysis for the Behavioral Sciences. Hillsdale, NJ: Lawrence Erlbaum Associates, Inc.

Cummins, D. D., Kintsch, W., Reusser, K., \& Weimer, R. (1988). The role of understanding in solving algebra word problems. Cognitive Psychology, 20, 405-438. 
Geary, D. C. (1994). Children's mathematical development: Research and practical applications. Washington, DC: American Psychological Association.

Greeno, J. G. (1983). Forms of understanding in mathematical problem solving. In S. G. Paris, G. M. Olson, \& H. W. Stevenson (Eds.), Learning and motivation in the classroom. Hillsdale, NJ: Lawrence Erlbaum Associates, Inc.

Greeno, J. G., \& the MMAP Group (1998). The situativity of knowing, learning, and research. American Psychologist, 53, 5-26.

Hall, R., Kibler, D., Wenger, E., \& Truxaw, C. (1989). Exploring the episodic structure of algebra story problem solving. Cognition and Instruction, 6, 223-283.

Hawkes, H. E., Luby, W. A., \& Touton, F. C. (1929). New second course in algebra. (Enlarged ed.). Boston: Ginn.

Heffernan, N. T., \& Koedinger, K. R. (1998). A developmental model for algebra symbolization: The results of a difficulty factors assessment. In Proceedings of the Twentieth Annual Conference of the Cognitive Science Society (pp. 484-489). Mahwah, NJ: Lawrence Erlbaum Associates, Inc.

Hiebert, J. (1982). The position of the unknown set and children's solutions of verbal arithmetic problems. Journal for Research in Mathematics Education, 13, 341-349.

Hudson, T. (1983). Correspondences and numerical differences between disjoint sets. Child Development, 54, 84-90.

Judd, C. H. (1908). The relation of special training to general intelligence. Educational Review, 36, 28-42.

Kaput, J. (in press). Employing children's natural powers to build algebraic reasoning in the context of elementary mathematics.

Katona, G. (1940). Organizing and memorizing. New York: Columbia University Press.

Katz, I. R., Friedman, D. F., Bennett, R. E., \& Berger, A. E. (1996). Differences in strategies used to solve stem-equivalent constructed response and multiple choice SAT mathematics items. ETS Research Rep. No. RR-96-20. Princeton, NJ: Educational Testing Service.

Kieran, C. (1992). The learning and teaching of school algebra. In D. Grouws (Ed.), Handbook of Research in Mathematics Teaching and Learning (pp. 390-419). New York: Macmillan.

Kilpatrick, J., Swafford, J. \& Findell, B. (2001). Adding it up: Helping children learn mathematics. Report of the Mathematics Learning Study Committee. National Research Council, National Academy Press: Washington, DC.

Kintsch, W. (1998). Comprehension: A paradigm for cognition. New York: Cambridge University Press.

Kintsch, W., and Greeno, J. G. (1985). Understanding and solving word arithmetic problems. Psychological Review, 92, 109-129.

Kirshner, D. (1989). The visual syntax of algebra. Journal for Research in Mathematics Education, 20, 274-287.

Koedinger, K. R., Alibali, M. W., \& Nathan, M. M. Trade-offs between grounded and abstract representations: Evidence from algebra problem solving. Manuscript submitted for peer review.

Koedinger, K. R., \& Anderson, J. R. (1990). Abstract planning and perceptual chunks: Elements of expertise in geometry. Cognitive Science, 14, 511-550.

Koedinger, K. R., Anderson, J. R., Hadley, W. H., \& Mark, M. A. (1997). Intelligent tutoring goes to school in the big city. International Journal of Artificial Intelligence in Education, 8, 30-43.

Koedinger, K. R., \& MacLaren, B. A. (2002). Developing a pedagogical domain theory of early algebra problem solving. CMU-HCII Tech Report 02-100. Retrieved from http://reports-archive.adm.cs.cmu.edu/hcii.html

Koedinger, K. R., \& Nathan, M. J. (1997, October). Teachers' notions of students' algebra problem-solving difficulties. Presentation to the James S. McDonnell Foundation Cognitive Studies for Educational Practice. 
Koedinger, K. R., \& Tabachneck, H. J. M. (1995). Verbal reasoning as a critical component in early algebra. Paper presented at the annual meeting of the American Educational Research Association, San Francisco, CA.

Koedinger, K. R., \& Terao, A. (2002). A cognitive task analysis of using pictures to support pre-algebraic reasoning. In C. D. Schunn \& W. Gray (Eds.), Proceedings of the Twenty-Fourth Annual Conference of the Cognitive Science Society. Mahwah, NJ: Lawrence Erlbaum Associates, Inc.

Kotovsky, K., Hayes, J. R. \& Simon, H. A. (1985). Why are some problems hard? Evidence from Tower of Hanoi. Cognitive Psychology, 17, 248-294.

Larkin, J. H., \& Simon, H. A. (1987). Why a diagram is (sometimes) worth ten thousand words. Cognitive Science, 11(1), 65-99.

Lewis, A. B., \& Mayer, R. E. (1987). Students' misconceptions of relational statements in arithmetic word problems. Journal of Educational Psychology, 79, 363-371.

MacLaren, B., \& Koedinger, K. R. (2002). When and why does mastery learning work: Instructional experiments with ACT-R "SimStudents." In S. A. Cerri, G. Gouarderes, \& F. Paraguacu (Eds.), Proceedings of the 6th International Conference on Intelligent Tutoring Systems, 355-366. Berlin, Germany: Springer-Verlag.

Mayer, R. E. (1982a). Different problem-solving strategies for algebra word and equation problems. Journal of Experimental Psychology: Learning, Memory, and Cognition, 8, 448-462.

Mayer, R. E. (1982b). Memory for algebra story problems. Journal of Educational Psychology, 74, 199-216.

Nathan, M. J., Kintsch, W., \& Young, E. (1992). A theory of algebra word problem comprehension and its implications for the design of computer learning environments. Cognition and Instruction, 9(4), 329-389.

Nathan, M. J., \& Koedinger, K. R. (2000a). Teachers' and researchers' beliefs of early algebra development. Journal of Mathematics Education Research, 31(2), 168-190.

Nathan, M. J., \& Koedinger, K. R. (2000b). An investigation of teachers' beliefs of students' algebra development. Cognition and Instruction, 18(2), 209-237.

Nathan, M. J., \& Koedinger, K. R. (2000c). Moving beyond teachers' intuitive beliefs about algebra learning. Mathematics Teacher, 93, 218-223.

Nathan, M. J., Koedinger, K. R., \& Alibali, M. W. (2001). Expert blind spot: When content knowledge eclipses pedagogical content knowledge. In L. Chen et al. (Eds.), Proceedings of the Third International Conference on Cognitive Science (pp. 644-648). Beijing, China: USTC Press.

Nathan, M. J., Long, S. D., \& Alibali, M. W. (2002). Symbol precedence in mathematics textbooks: A corpus analysis. Discourse Processes, 33, 1-21.

Nathan, M. J., Stephens, A. C., Masarik, D. K., Alibali, M. W., \& Koedinger, K. R. (2002). Representational fluency in middle school: A classroom based study. Proceedings of PME-NA XXXIII (the North American Chapter of the International Group for the Psychology of Mathematics Education).

National Council of Teachers of Mathematics. (2000). Principles and standards for school mathematics. ISBN 0-87353-480-8. Reston, VA: Author. Retrieved from http://standards.nctm.org/protoFINAL.

Nhouyvanisvong, A. (1999). Enhancing mathematical competence and understanding: Using open-ended problems and informal strategies. Unpublished doctoral dissertation, Carnegie Mellon University, Pittsburgh, PA.

Nunes, T., Schliemann, A. D., \& Carraher, D. W. (1993). Street mathematics and school mathematics. New York: Cambridge University Press.

Paige, J. M., \& Simon, H. A. (1966). Cognitive processes in solving algebra word problems. In B. Kleinmuntz (Ed.), Problem Solving (pp. 51-119). New York: Wiley.

Payne, S. J., \& Squibb, H. R. (1990). Algebra mal-rules and cognitive accounts of error. Cognitive Science, $14,445-491$. 
Reber, A. S. (1967). Implicit learning of artificial grammars. Journal of Learning and Verbal Behavior, 6, 855-863.

Reed, S. K. (1998). Word problems: Research and curriculum reform. Mahwah, NJ: Lawrence Erlbaum Associates, Inc.

Resnick, L. B. (1987). Learning in school and out. Educational Researcher, 16(9), 13-20.

Riley, M. S., \& Greeno, J. G. (1988). Developmental analysis of understanding language about quantities and of solving problems. Cognition and Instruction, 5(1), 49-101.

Romberg, T. A., \& de Lange, J. (in press). Monitoring student progress. In T. A. Romberg (Ed.), Insight stories: Assessing middle school mathematics. New York: Teachers College Press.

Roth, W.-M. (1996). Where is the context in contextual word problems?: Mathematical practices and products in grade 8 students' answers to story problems. Cognition and Instruction, 14(4), 487-527.

Servan-Schreiber, E., \& Anderson, J. R. (1990). Learning artificial grammars with competitive chunking. Journal of Experimental Psychology: Learning, Memory, and Cognition, 16, 592-608.

Siegler, R.S., \& Lemaire, P. (1997). Older and younger adults' strategy choices in multiplication: Testing predictions of ASCM via the choice/no-choice method. Journal of Experimental Psychology: General, 126, 71-92.

Singapore Ministry of Education (1999). Primary mathematics 6A Third Edition. Curriculum Planning and Development Division. Singapore: Federal Publications. Available at www.singaporemath.com

Sleeman, D. (1984). An attempt to understand students' understanding of basic algebra. Cognitive Science 8 (1984) 387-412.

Stern, E. (1997). Das Lösen mathematischer Textaufgaben [Mathematical word problem solving]. In F. E. Weinert \& A. Helmke (Hrsg.), Entwicklung im Grundschulalter [Development in elementary school]. (S.157170), Weinheim, Germany: Psychologie Verlags Union.

Sweller, J. (1988). Cognitive load during problem solving: Effects on learning. Cognitive Science, 12, 257-286.

Tabachneck, H. J. M., Koedinger, K. R., \& Nathan, M. J. (1994). Toward a theoretical account of strategy use and sense making in mathematics problem solving. In Proceedings of the Sixteenth Annual Conference of the Cognitive Science Society (pp. 836-841). Hillsdale, NJ: Lawrence Erlbaum Associates, Inc.

Verzoni, K., \& Koedinger, K. R. (1997). Student learning of negative number: A classroom study and difficulty factors assessment. Paper presented at the annual meeting of the American Educational Research Association, Chicago, IL.

Zhang, J., \& Norman D. A. (1994). Representations in distributed cognitive tasks. Cognitive Science, $18,87-122$. 